\title{
IMPRESSÕES DE ESTUDANTES SOBRE O TRABALHO COM RESOLUÇÃO DE PROBLEMAS E TEMÁTICAS EM AULAS DE QUÍMICA
}

STUDENTS 'IMPRESSIONS ABOUT WORK WITH PROBLEM SOLVING AND THEMATIC IN CHEMISTRY CLASSES

DOI: 10.23926/RPD.2526-2149.2020.v5.n2.p1057-1075.id718

\section{Édila Rosane Alves da Silva \\ Mestre em Educação em \\ Ciências (UFSM) \\ edilaas@hotmail.com}

\section{Mara Elisangela Jappe \\ Goi}

Doutora em Educação

(UFRGS)

Professora na Universidade

Federal do Pampa

(UNIPAMPA)

maragoi28@gmail.com
Resumo: Este trabalho apresenta e discute os resultados obtidos a partir da implementação de uma proposta didática desenvolvida com estudantes do $3^{\circ}$ Ano do Ensino Médio de uma escola da rede pública do Estado do Rio Grande do Sul, que objetivou identificar a possível influência da metodologia de Resolução de Problemas nos processos de ensino e de aprendizagem de conteúdos escolares, mediada pela temática "Drogas". A escolha do assunto faz parte de um levantamento preliminar sobre temas com relevância social para serem tralhados no ambiente escolar. Os dados produzidos respostas a questionários e produtos das sistematizações - foram analisados por meio da Escala de Likert. A partir desta pesquisa, evidenciou-se as potencialidades do uso da Resolução de Problemas a partir da temática proposta, tais como o desenvolvimento de habilidades cognitivas para elaboração de estratégias, reflexão crítica, exposição de argumentação, entre outras competências desenvolvidas pelos estudantes.

Palavras-chave: Temáticas. Resolução de Problemas. Educação Básica

\begin{abstract}
This paper presents and discusses the results obtained from the development of a didactic proposal with students from 3rd grade of high school, at a public school from Rio Grande do Sul, which aimed to identify possible influence of the methodology Problem Solving in teaching and learning processes of school content, mediated by the theme "Drugs". The choice of subject is part of a preliminary survey about themes with social relevance to be discussed at school. The data obtained - responses to questionnaires and systematization products - were analyzed using the Likert Scale. From this research, were evidenced the potentialities of Problem Solving, such as the development of new cognitive skills for the formulation of strategies, critical reflection, exposition of arguments, among other skills already developed by the students.
\end{abstract}

Keywords: Thematic. Problem solving. Basic education. 


\section{INTRODUÇÃO}

Neste trabalho discute-se as impressões de estudantes do $3^{\circ}$ Ano do Ensino Médio de uma escola da rede estadual de ensino do Rio Grande do Sul, sobre uma proposta didática que considerou à articulação entre a Metodologia de Resolução de Problemas e temáticas. A temática adotada referiu-se às drogas, tanto lícitas como ilícitas e foi desenvolvida na disciplina de Química, sob o título "Drogas, o que elas têm a oferecer?”.

A referida proposta foi desenvolvida considerando-se um levantamento preliminar sobre o alto índice de consumo de drogas entre adolescentes no município em que o trabalho foi realizado. A proposição do assunto compõe um estudo realizado no componente curricular de Integração das Ciências II, ofertado no Curso de Ciências Exatas Licenciatura, da Universidade Federal do Pampa (UNIPAMPA), para o qual foram elencadas temáticas pertinentes de serem trabalhadas no ambiente escolar por tratarem de assuntos com relevância social para a comunidade local.

A utilização de propostas didáticas com ênfase no contexto social, encontra respaldo nos diversos documentos que normatizam a educação brasileira, entre eles a Base Nacional Comum Curricular (BNCC) que salienta a necessidade de utilizar o conhecimento curricular contextualizado pela realidade local, social e individual da escola e seus educandos (BRASIL, 2018). Para alguns autores (FREIRE, 2002; SILVA, MARCONDES, 2014; AULER, 2002; 2003; SANTOS, 2007; DELIZOICOV, ANGOTTI, 1992), o indicativo para a contextualização do ensino se apoia na ideia do uso de temas, que por sua vez, apresenta-se "como um meio de possibilitar ao aluno uma educação para a cidadania concomitantemente à aprendizagem significativa de conteúdos" (SILVA, MARCONDES, 2014, p. 16).

De acordo com Silva (2020, p. 43), a relação entre conceitos e contextos passa a exercer "papel fundamental na abrangência da complexidade das relações entre ambos, rompendo com a centralidade das disciplinas, substituindo-as por aspectos mais globalizados" em todos os níveis de ensino. Nessa perspectiva de organização educacional estruturada por temas, os conceitos científicos são subordinados ao assunto e as situações que o originam (DELIZOICOV, ANGOTTI, PERNAMBUCO, 2002).

No entanto, entende-se que tais relações não devem assumir um caráter superficial de descrição científica dos fatos e situações da rotina dos estudantes, como apontam alguns estudos (SANTOS; MORTIMER, 1999a; 1999b), reduzindo-os a meras exemplificações. Em sentido contrário, pode-se ampliar essa visão reducionista oportunizando aos estudantes uma formação 
crítica, abrindo "espaços para dimensões sociais, englobando aspectos ambientais, políticos, econômicos, éticos e culturais" (SILVA, 2020, p. 59).

No intuito de dissipar possíveis superficialidades, optou-se por unir a perspectiva temática à Metodologia de Resolução de Problemas. A opção por esse método de Ensino se justifica por:

[...] basear-se na apresentação de situações abertas e sugestivas que exijam dos alunos uma atitude ativa ou um esforço para buscar suas próprias respostas, seu próprio conhecimento. $\mathrm{O}$ ensino baseado na solução de problemas pressupõe promover nos alunos o domínio de procedimentos, assim como a utilização dos conhecimentos disponíveis, para dar resposta a situações variáveis e diferentes (ECHEVERRÍA; POZO, 1998, p. 9).

Em contrapartida, o interesse em trabalhos a partir de assuntos temáticos deve-se pela flexibilidade curricular em incluir questões socialmente relevantes de acordo com as necessidades locais e sociais, como indicado na BNCC (BRASIL, 2018). Acredita-se que a articulação de assuntos relevantes socialmente, associados aos conteúdos específicos necessários para o entendimento do mesmo, propicia aos estudantes melhores condições para enfrentarem a realidade e tomarem suas próprias decisões com relação ao uso de drogas. Nesse sentido, concorda-se que o saber científico favorece a habilidade reflexiva e o empenho pelo aprendizado das situações que o cercam, ampliando a capacidade de resolver problemas emergentes, proporcionando assim, seu progresso intelectual (LAUDAN, 1977).

A partir do exposto, objetiva-se relatar à experiência vivenciada por meio de uma proposta didática implementada em uma turma de $3^{\circ}$ Ano do Ensino Médio, na disciplina de Química, sobre a temática Drogas, especificamente a respeito da impressão dos estudantes participantes desse trabalho. Com o propósito de embasar essa pesquisa, prosseguir-se-á com um estudo sobre as orientações indicadas nos documentos oficiais para o trabalho com temas na Educação Básica, seguida da apresentação das características da metodologia de Resolução de Problemas e sua implementação no Ensino de Ciências.

\section{REFERENCIAL TEÓRICO}

\subsection{ENSINO POR EIXOS TEMÁTICOS}

$\mathrm{Na}$ área de ensino, a palavra Temas é amplamente defendida pelos documentos oficiais educativos e pelos diversos referenciais que a adotam em sua variabilidade. Nesses documentos o Ensino por eixos temáticos pode ser observado por meio dos Temas Transversais para o Ensino Fundamental, dos Temas Estruturadores e temas com caráter transversal para o Ensino 
Médio e, atualmente, pela Base Nacional Comum Curricular (BRASIL, 2018) em ambos os níveis educacionais.

De acordo com a BNCC (BRASIL, 2018), os currículos devem ser compostos por uma matriz básica comum e uma parte diversificada, considerando as relações entre ambas, estabelecendo a contextualização pela realidade local, social e individual da escola e de seus estudantes, sugerindo uma forma de ensino que promova a formação integral do educando. A respeito da contextualização de conteúdos, esta permite à aproximação dos conceitos estudados em sala de aula com o cotidiano dos estudantes, promovendo o interesse pelo conhecimento. Para Halmenschlager (2014, p. 26), esses fatores amparam à incorporação de assuntos temáticos na Educação Básica, possibilitando minorar a linearidade e fragmentação dos conteúdos escolares em prol da interdisciplinaridade e contextualização de acordo com que é proposto nas Diretrizes Curriculares para o Ensino Médio.

Especificamente, no que diz respeito ao Ensino de Química, os Parâmetros Curriculares Nacionais para o Ensino Médio- PCNEM (BRASIL, 2000), sugerem a inclusão de temas para a contextualização do conhecimento químico, bem como para estabelecer e ampliar suas relações com as demais áreas científicas e tecnológicas. Nessa perspectiva, a formulação de atividades educativas balizadas por temáticas tem como objetivo a participação ativa e construtiva do estudante em seu meio social, como descrito a seguir:

\footnotetext{
$\mathrm{O}$ ensino e a aprendizagem da participação têm como suporte básico a realidade escolar para o uso efetivo dos procedimentos aprendidos, para a promoção das capacidades que se quer desenvolver. Assim, devem ser eleitos métodos e atividades que ofereçam experiências de aprendizagem ricas em situações de participação, nas quais os alunos possam opinar, assumir responsabilidades, colocar-se, resolver problemas e conflitos e refletir sobre as consequências de seus atos (BRASIL, 1997, p. 41).
}

Esse documento enfatiza a escolha de métodos que oportunizem o estímulo da aprendizagem que se pretende desenvolver, propiciando possibilidades para implementação de inúmeras abordagens metodológicas que visem o favorecimento da construção da aprendizagem a que este documento se refere. Dentre as diversas opções metodológicas indicadas na literatura, adotou-se a Resolução de Problemas por ser uma estratégia com amplo potencial de ensino e aprendizagem na área de Ensino de Ciências, como demonstram pesquisas anteriormente realizadas (LEME, 2001; GOI, 2014; MENDONÇA, 2017; MEDEIROS, 2019; SILVA, 2020). 


\subsection{ReSOluÇão de Problemas.}

A metodologia de Resolução de Problemas é amparada por variadas vertentes dependendo da área em que é desenvolvida. No meio educacional, pode ser fundamentada em diversos aspectos, entre eles em concepções epistemológicas e pedagógicos, o que assegura uma amplitude da perspectiva de ensino e aprendizagem com vistas a oportunizar uma formação capaz de instruir seus educandos para o enfrentamento dos desafios da sua realidade social.

Amparada pela epistemologia, ramo da filosofia que explora o conhecimento científico, pode viabilizar estudos dos princípios da ciência, suas hipóteses e resultados em uma perspectiva de determinação dos seus fundamentos lógicos, valor e relevância prática. Nesse sentido, metodologias embasadas em tendências epistemológicas podem proporcionar ao estudante uma visão histórica e filosófica dos fatos com vistas a produção do conhecimento, sua consistência, validade e limites. Dentre os diversos filósofos existentes, optou-se por explorar nesse ensaio a teoria de Larry Laudan, "por se entender que este autor reitera o significativo valor da metodologia de Resolução de Problemas para o papel do desenvolvimento científico e educacional na área do Ensino de Ciências” (SILVA; GOI, 2019a, p. 109).

Para Laudan (1986, p. 18), “a ciência é essencialmente uma atividade de solução de problemas" que progride por meio da racionalidade em escolhas teóricas progressivas e a coexistência de teorias rivais não cumulativas, mas comparativas. O autor utiliza o termo 'Evolução Científica' para recorrer ao progresso da ciência, por meio da Resolução de Problemas. Há progresso, quando novas teorias solucionam maior número de problemas que as teorias anteriores, reduzindo ao mínimo os problemas conceituais e anômalos.

Laudan (1978, p. 23) propõe uma classificação para os problemas, sendo eles empíricos e conceituais. "Os problemas empíricos são, portanto, problemas de primeira ordem, ou seja, questões substantivas acerca dos objetos que constituem o domínio de determinada ciência". Podem ser divididos em três tipos: problemas não resolvidos, resolvidos e anômalos.

Os problemas não resolvidos são aqueles que ainda não foram adequadamente solucionados por nenhuma teoria, seja por não apresentarem um caráter genuíno ou por não explicitar a que domínio da ciência a teoria em questão pertence. Os problemas resolvidos são aqueles que determinada teoria já solucionou, não sendo mais considerado como uma incógnita pela comunidade científica e, os problemas anômalos são os problemas que apresentam certa 
incoerência em relação à teoria que potencialmente poderia solucioná-lo, sendo resolvido por uma teoria rival (LAUDAN, 1986).

A segunda taxonomia proposta por Laudan (1986), refere-se aos problemas conceituais, que muitas vezes foram ignorados por epistemólogos ao longo dos tempos, por não se adaptar a crença da produção científica baseada apenas em dados empíricos. Os problemas conceituais são apresentados por teorias e podem ser considerados de "ordem superior acerca da fundamentação das estruturas conceituais que foram concebidas para responder às questões de primeira ordem (empíricos)" (LAUDAN, 1986, p. 68).

Os problemas conceituais subdividem-se em dois grupos, os internos e externos. Os internos surgem quando uma determinada teoria apresenta inconsistências internas se tornando contraditória ou quando suas categorias de análise são pouco claras, gerando ambiguidade ou circularidade conceituais na própria teoria (LAUDAN, 1986).

A teoria de Laudan sugere que o progresso científico ocorre por meio da elucidação de problemas, sejam eles empíricos e/ou conceituais, o que corrobora com as práticas de pesquisas caracterizadas por Santos e Goi (2012) como um conjunto de métodos e estudos que podem ser utilizados na investigação de problemas e construção de teorias (SILVA; GOI, 2019a). Essa abordagem epistemológica influência na metodologia de Resolução de Problemas, ao passo que defende o viés educativo fundamentado na construção ativa do conhecimento pelo educando, criando neles hábitos e atitudes de enfrentamento da "aprendizagem como um problema para o qual deve ser encontrada uma resposta" (POZO; ECHEVERRIA, 1998, p. 14).

A metodologia de ensino a Resolução de Problemas visa a promoção do domínio de habilidades e estratégias que permitam ao estudante aprender a aprender, bem como a utilização dos saberes disponíveis para responder a situações variáveis e diferentes (POZO, 1998). É relevante salientar, que esse aprender a aprender em nada remonta o ensino por redescoberta, extremamente criticado nas décadas de 1960 e 1970 até os dias atuais, mas um aprender através da pesquisa, como sinalizam Bruner (2008) e Praia (2012).

Algumas pesquisas (LOPES, 1994; POLYA, 1995; ECHEVERRÍA, 1998; GOI, 2014, ANO; ONUCHIC, 2014; JUNIOR, NETO, 2015, MEDEIROS, 2019) também apontam para os benefícios no trabalho com problemas em diversas áreas do conhecimento. Especificamente na área de Ciências da Natureza, constata-se resultados atrelados ao "desenvolvimento de habilidades e competências investigativas, aumento do senso crítico e da criatividade, autonomia nos processos de aprendizagem, motivação para iniciação na pesquisa, dentre outros (SILVA, 2020). 
No campo das Ciências Naturais, a finalidade da inclusão da metodologia de Resolução de Problemas em seus currículos se justifica pela promoção da aprendizagem dos processos científicos, tecnológicos e da natureza das ciências com vistas a sua utilização para a formulação e solução de problemas no meio social do estudante. Desígnios semelhantes são apontados como finalidade para a Educação Básica, segundo a Base Nacional Comum Curricular:

\begin{abstract}
A sociedade contemporânea está fortemente organizada com base no desenvolvimento científico e tecnológico. Da metalurgia, que produziu ferramentas e armas, passando por máquinas e motores automatizados, até os atuais chips semicondutores, ciência e tecnologia vêm se desenvolvendo de forma integrada com os modos de vida que as diversas sociedades humanas organizaram ao longo da história. No entanto, o mesmo desenvolvimento científico e tecnológico que resulta em novos ou melhores produtos e serviços também pode promover desequilíbrios na natureza e na sociedade. Para debater e tomar posição sobre alimentos, medicamentos, combustíveis, transportes, comunicações, contracepção, saneamento e manutenção da vida na Terra, entre muitos outros temas, são imprescindíveis tanto conhecimentos éticos, políticos e culturais quanto científicos. Isso por si só já justifica, na educação formal, a presença da área de Ciências da Natureza, e de seu compromisso com a formação integral dos alunos (BRASIL, 2018, p. 320).
\end{abstract}

De acordo com Silva (2020), "Para que essa meta seja alcançada é necessário que à escola ofereça condições para essa aprendizagem, valorizando aspectos sociais que viabilizem à introdução de conceitos curriculares”. Corroborando com o exposto, já em 1998 Pozo (p. 69), argumentava que "se pretendemos que os alunos usem os seus conhecimentos para resolver problemas, é necessário ensinar-lhes ciências resolvendo problemas".

Quanto à caracterização do que vem a ser um problema, diversos autores apresentam suas interpretações, entre eles Silva $(2017$, p. 8) ao citar Laudan (1986), que sugere a definição de problemas como "condições desafiadoras que permitem desenvolver conhecimentos relacionados à ciência e auxiliam na atuação científica em situações presentes em sala de aula nas disciplinas de ciências". Para Echeverría e Pozo (1998, p. 13-14), um "problema é considerado uma situação na qual um indivíduo ou um grupo quer ou necessita resolver e para o qual não se dispõe de um caminho rápido e direto que lhe leve à solução".

A distinção entre problemas e exercícios é apontada por Pozo (1998) ao analisar os mecanismos disponíveis para sua solução, sendo considerado um exercício aqueles que podem levar a resolução imediata, sem buscas ou procedimentos que permitam avançar nos conhecimentos já disponíveis. Para D’Amore (2007) problemas são aqueles que priorizam processos ativos para a construção de saberes em detrimento de atividades que privilegiam a execução de tarefas priorizando resultados. 
Outras características que podem vir a diferenciar problemas de exercícios, referem-se à aspectos relacionados aos enunciados, disponibilidade de dados, conceitos ou regras com aplicações gerais, podendo ser ampliado a outras tarefas semelhantes e resultados que priorizam uma resposta única, como atributos dos exercícios. Já questões consideradas desafiadoras, apresentam uma legenda com "situações sugestivas e algumas orientações, exigindo uma maior reflexão para sua resolução e, no qual pode não haver somente um único meio de solução, levando o estudante a estabelecer um aspecto dinâmico na demanda por respostas" (SILVA, 2017, p. 8).

Os tipos de problemas incluem uma variada gama de distinções, porém destacam-se as categorias propostas por Pozo (1998, p. 78) para o Ensino de Ciências que são classificados como qualitativos, quantitativos e pequenas pesquisas. Os problemas qualitativos "são aqueles que os alunos precisam resolver através de raciocínio teórico, sem necessidade de cálculos numéricos e que não requerem manipulação experimental". Os problemas denominados quantitativos "são aqueles que o aluno deve manipular dados numéricos para chegar a uma solução, seja ela numérica ou não, são fundamentados em cálculos matemáticos, comparação de dados e utilização de fórmulas" (POZO, 1998, p.82). As pequenas pesquisas são problemas baseados em atividades práticas, para os quais é necessário elaborar suposições, traçar um plano de ação, esboçar estratégias de trabalho e refletir sobre os resultados alcançados.

A partir das concepções apresentadas, acredita-se que a finalidade do Ensino de Ciências poderia pautar-se na busca pelo desenvolvimento de competências e habilidades que permitam aos estudantes atuarem de forma responsável na solução de problemas cotidianos. Nesse contexto, a Metodologia de Resolução de Problemas evidência potencialidades para a conquistas dessas metas, na medida que, oportuniza os estudantes uma aproximação de situações desafiadoras por meio dos problemas propostos para sua resolução. Essas situações podem derivar de temáticas locais ou polêmicas que demandem certo conhecimento científico para sua melhor solução, como é sugerido pela BNCC.

\section{Caminhos metodológicos}

O presente trabalho apresenta abordagem predominantemente qualitativa, caracterizando-se como estudo de caso. A pesquisa qualitativa tem como objetivo isolar causas e efeitos, operacionalizar relações teóricas, com vistas à mensuração dos fenômenos e a elaboração de propostas de investigação que permitam desenvolver diligências para a formulação de leis gerais (FLICK, 2009). Já o método de estudo de caso é descrito por Gil 
(2017, p. 54) "como um delineamento para a investigação de um fenômeno contemporâneo dentro do seu contexto real".

Esse ensaio apresenta um recorte da pesquisa desenvolvida, no qual são retratadas as impressões dos estudantes sobre a metodologia de Resolução de Problemas articulada à temática proposta. Ao início da abordagem didática, aplicou-se um Questionário Inicial do tipo Likert (ALEXANDRE et. al, 2003) que teve por objetivo verificar as opiniões dos estudantes em relação as atividades desenvolvidas. Ao final das intervenções, novamente foi aplicado um questionário, com isso analisou-se aspectos relacionados a opinião dos estudantes sobre o uso das metodologias propostas em aulas de Química.

Neste questionário utilizou-se uma escala de 1 a 5 (1= DT Discordo Totalmente; 2= D Discordo; 3= NO Não tenho opinião ou indeciso; 4= C Concordo; 5= CP Concordo Completamente) indicando o grau de concordância dos estudantes sobre as afirmações que compunham os questionários. A análise das respostas baseou-se no cálculo de Ranking Médio, no qual a concordância dos informantes em cada item se aproxima dos valores extremos de 1 a 5, indicando ideias implícitas.

\subsection{CONTEXTO DA PESQUISA}

Essa pesquisa foi realizada por meio de intervenções em sala de aula na disciplina de Química no $3^{\circ}$ Ano do Ensino Médio, totalizando três aulas semanais, pelo período de um semestre letivo, realizados em uma escola da rede pública de ensino no Estado do Rio Grande do Sul. A proposta foi realizada em três etapas conforme apresentado na Figura 1. Nesse artigo apresenta-se de maneira mais detalhada os dados relacionados a análise dos questionários respondidos pelos estudantes no início e final das intervenções didáticas.

Figura 1: 
Figura 1 - Etapas de desenvolvimento da proposta didática na disciplina de Química

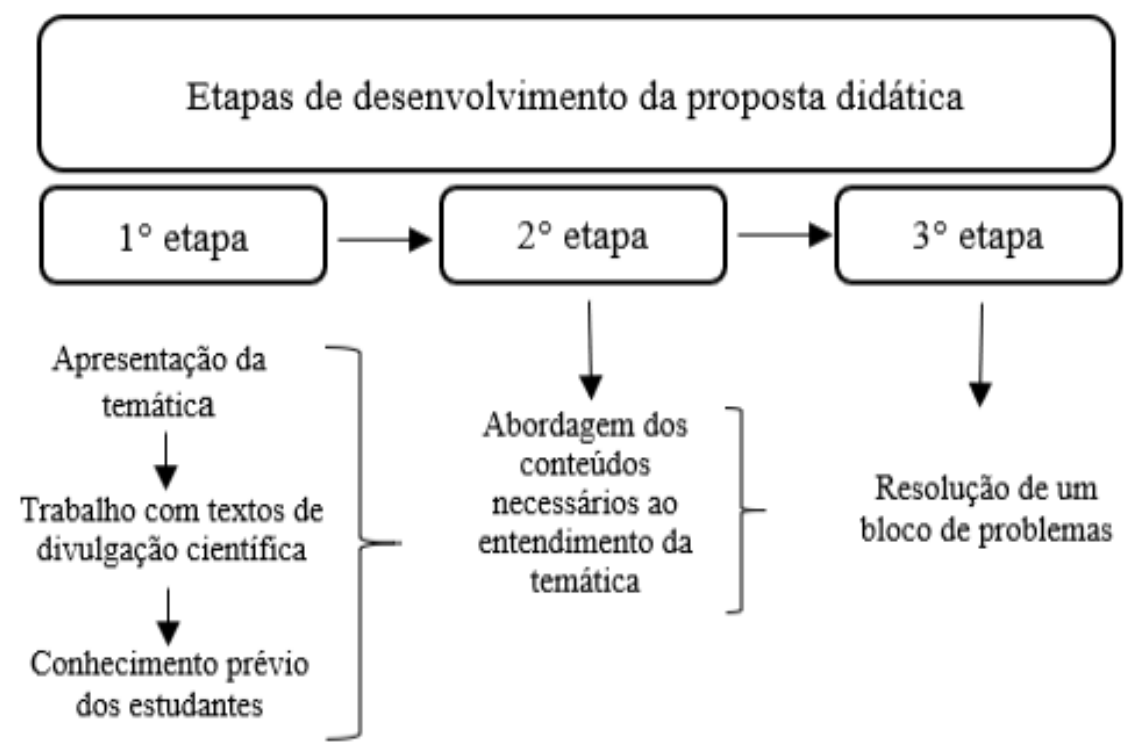

Fonte: Autores

\section{DisCuSSÕES DOS DADOS E RESULTADOS DA INVESTIGAÇÃo}

\subsection{ANÁLISE do QUESTIONÁRIO INICIAL}

A análise do Questionário Inicial revelou aspectos significativos sobre o ponto de vista dos estudantes em relação à disciplina de Química e dos esforços despendidos com relação a mesma. No Quadro 1 estão elencadas as questões do questionário inicial tipo likert, bem como seus escores.

Quadro 1 - Questionário inicial sobre a disciplina de Química e autoavaliação dos estudantes

\begin{tabular}{|c|c|}
\hline Quanto à disciplina de Química & Escore \\
\hline É uma disciplina que contribui significativamente para minha vida e sociedade & 3,188 \\
\hline Participo com interesse das aulas & 3,379 \\
\hline Dedico certo esforço para acompanhá-la & 3,902 \\
\hline Exige muito raciocínio & 4,093 \\
\hline É uma disciplina de fácil compreensão & 3,521 \\
\hline Autoavaliação quanto à disciplina de Química & 3,235 \\
\hline Tenho a impressão que a cada aula aprendo novos conhecimentos & 3,712 \\
\hline Acredito que eu poderia ter dedicado mais tempo e atenção à disciplina & 4,236 \\
\hline
\end{tabular}

Fonte: Autores

Os estudantes concordam que a disciplina de Química exige bastante raciocínio e que, por isso necessitam de esforço para acompanhá-la. Em contrapartida, parecem não ter uma opinião formada quanto ao grau de compreensão da disciplina, sua contribuição para vida e sociedade, bem como a sua participação em sala de aula. Parecer semelhante é descrito nos 
Parâmetros Curriculares Nacionais (BRASIL, 2000), ao destacar uma pesquisa realizada com estudantes do Ensino Médio. Segundo os dados obtidos no referido estudo os jovens não observam relação entre a Química escolar e fatos de seu cotidiano, como pode ser verificado a seguir:

\begin{abstract}
Pesquisa recente com jovens de Ensino Médio revelou que estes não veem nenhuma relação da Química com suas vidas nem com a sociedade, como se o iogurte, os produtos de higiene pessoal e limpeza, os agrotóxicos ou as fibras sintéticas de suas roupas fossem questões de outra esfera de conhecimento, divorciadas da Química que estudam na escola (BRASIL, 2000, p. 79).
\end{abstract}

Com relação à autoavaliação os estudantes consideram-se bons alunos, porém não apresentam uma concordância definida sobre o aprendizado de novos conhecimentos nas aulas e sua dedicação para com as mesmas. Percebe-se que eles acreditam que é necessário o uso de raciocínio lógico em aulas de Química, sendo preciso certo esforço para acompanhá-las. Além disso, os educandos se julgam empenhados no que tange as responsabilidades imbuídas às atividades experimentais e, não tem uma opinião formada quanto o grau de compreensão da disciplina e suas contribuições para o cotidiano, não estando convencidos quanto à aprendizagem de novos conhecimentos a cada aula.

Isso é concebível pelo fato de os alunos não conseguirem atribuir significados a conceitos trabalhados em sala de aula, o que pode ser justificado pela falta de articulação entre os conteúdos científicos e a realidade vivenciada pelos mesmos, fato este, que distância a ciência escolar dos problemas reais. Tais questões sinalizam para a contextualização dos conhecimentos, que se configura "como um meio de possibilitar ao aluno uma educação para a cidadania concomitantemente à aprendizagem significativa de conteúdos" (SILVA; MARCONDES, 2014, p. 16).

Para Freire (2002), a contextualização do conhecimento mediada por temáticas vivenciadas no meio social, possibilita aos estudantes se reconhecer como sujeito ativo no ambiente em que estão inseridos, a medida que, o conhecimento não é tratado de forma estática e independente de suas realidades. Nesse contexto, o autor defende que a estrutura curricular escolar pode ser embasada em temáticas que representem a realidade da comunidade na qual o estudante está inserido.

Alinhado a essa perspectiva, Santos (2007) sinaliza que os currículos escolares devem considerar as "inter-relações entre explicação científica, planejamento tecnológico, solução de problemas e tomada de decisão sobre temas práticos de importância social”, como forma para a construção de saberes, habilidades e valores que permitam ao estudante refletir e deliberar 
sobre as demandas atuais com responsabilidade. De acordo com Santos e Mortimer (2002), a adoção de assuntos derivados de problemas, sobre os quais recaiam diferentes crenças e valores, permite ao estudante avaliar e analisar as situações em estudo, favorecendo a compreensão das relações sociais e científicas, bem como suas influências na sociedade contemporânea.

\subsection{ANÁliSE do QUESTIONÁRIO FinAL}

Posterior às intervenções didáticas realizadas por intermédio da Metodologia de Resolução de Problemas e assuntos temáticos, um segundo questionário foi aplicado com o intuito de verificar a opinião dos estudantes quanto aos problemas sugeridos, trabalhos orais e escritos, trabalho através da metodologia de Resolução de Problemas, seguida por uma autoavaliação. O questionário respondido nesta etapa do processo didático seguiu o mesmo modelo do questionário inicial. É importante lembrar que o questionário final tem questões similares ao inicial, mas não idênticas, pois o objetivo foi de averiguar as opiniões dos estudantes em relação ao uso da metodologia de Resolução de Problemas articulada à temática trabalhada.

Quadro 2 - Questionário final sobre as atividades mediadas pela Metodologia de Resolução de Problemas

\begin{tabular}{|l|c|}
\hline \multicolumn{1}{|c|}{ Quanto aos problemas sugeridos } & Escore \\
\hline Os problemas exigiram pouco raciocínio & 2,569 \\
\hline O grupo compreendeu o problema, sem grandes dificuldades & 3,356 \\
\hline Pesquisei muito para chegar nas estratégias adequadas & 4,389 \\
\hline A linguagem utilizada foi de difícil compreensão & 4,048 \\
\hline Os dados para a resolução dos problemas não necessitam de pesquisa & 2,640 \\
\hline Foram de fácil compreensão & 4,154 \\
\hline \multicolumn{1}{|c|}{ Quanto aos trabalhos orais e escritos } & Escore \\
\hline Os relatórios seguem o mesmo esquema que adotávamos antes desse trabalho & 4,141 \\
\hline $\begin{array}{l}\text { Tenho dificuldade em descrever as estratégias adotadas para a resolução dos } \\
\text { problemas }\end{array}$ & 2,641 \\
\hline $\begin{array}{l}\text { Acho importantes os trabalhos/ relatórios descritivos, pois ajudam na compreensão do } \\
\text { problema }\end{array}$ & 4,057 \\
\hline $\begin{array}{l}\text { Acho desnecessária a realização de relatórios/ e ou apresentação de seminários orais } \\
\text { após cada resolução de problemas }\end{array}$ & 2,297 \\
\hline Senti dificuldade em expor o meu pensamento para o grupo & 4,227 \\
\hline Auxiliaram na compreensão dos problemas sugeridos & 4,413 \\
\hline & Escore \\
\hline $\begin{array}{l}\text { Percebi que esse trabalho pode ser significativo para uma melhor compreensão das } \\
\text { aulas experimentais. }\end{array}$ & 4,213 \\
\hline Esse trabalho foi diferente do que estávamos habituados a realizar & 4,272 \\
\hline $\begin{array}{l}\text { O tempo foi suficiente para realizarmos as atividades. } \\
\text { Senti muitas dificuldades em compreender o trabalho através de problemas } \\
\text { experimentais }\end{array}$ & 3,355 \\
\hline Parece que pouco contribui para a minha aprendizagem. & 2,856 \\
\hline $\begin{array}{l}\text { A resolução de problemas não diferiu em nada ao trabalho que já estávamos } \\
\text { realizando nesse ano letivo. }\end{array}$ & 2,784 \\
\hline Foi um trabalho de difícil compreensão & 2,341 \\
\hline & Escore \\
\hline
\end{tabular}




\begin{tabular}{|l|l|}
\hline $\begin{array}{l}\text { Colaborei com o grupo, assumindo de forma responsável todos os problemas } \\
\text { propostos }\end{array}$ & 4,642 \\
\hline Tenho a impressão que a cada aula aprendi novos conhecimentos & 4,590 \\
\hline $\begin{array}{l}\text { Acredito que desperdicei o tempo dedicado ao trabalho sobre Resolução de } \\
\text { Problemas }\end{array}$ & 2,499 \\
\hline As atividades motivaram-me para a resolução dos problemas. & 4,289 \\
\hline
\end{tabular}

Fonte: autores

Quanto aos problemas sugeridos, os estudantes concordam que tiveram que realizar pesquisas para obter as estratégias adequadas para solução, o que corrobora com Silva (2020, p. 66) ao salientar que "o desenvolvimento do potencial intelectual por meio da Resolução de Problemas ocorre quando os indivíduos encontram regularidades e relações na solução de questões mediante o ato de pesquisar". Para Bruner (2008), os processos desenvolvidos no decorrer da solução de problemas (pesquisas, levantamento de hipóteses, formulação de estratégias) pode favorecer a obtenção de conhecimentos para utilização na vida cotidiana e significa, na concepção do autor, aprender a lidar com a tarefa de aprender.

Quanto à compreensão dos problemas, os alunos não tiveram grandes dificuldades devido a linguagem facilitada. Isso pode ser evidenciado por Polya (1995) ao argumentar que para resolver problemas, primeiro é necessária uma compreensão prévia da tarefa que não se resume apenas na linguagem, mas em assumir a situação como tal, a ponto de despertar disposição na busca de soluções.

Sobre os trabalhos orais e escritos desenvolvidos durante à implementação da proposta didática, os estudantes concordam que estes auxiliaram na compreensão do problema, bem como admitem dificuldade em expor ao grupo seus pensamentos de forma oral, o que não ocorreu quanto à forma escrita. De acordo com alguns autores (MENDONÇA, 2017; SILVA; GOI, 2019b), a argumentação pode se manifestar como uma habilidade que proporciona o vínculo entre os conhecimentos já armazenados na estrutura cognitiva do estudante e os novos saberes, por meio da linguagem. Em contrapartida, atividades representadas por meio da escrita podem propiciar uma maior reflexão sobre as estratégias adotadas para a solução dos problemas. Para Pozo e Echeverría (1998) tais habilidades se justificam pela necessidade, ao solucionar problemas, de colocar em ação uma série de conhecimentos que precisam adaptarse as caraterísticas de cada situação.

Com relação a proposta de trabalho por meio da utilização da metodologia de Resolução de Problemas, os estudantes parecem concordar que esta estratégia de ensino se diferenciou de outras, anteriormente desenvolvidas na disciplina de Química. Além disso, os dados apontam para a significância atribuída a essa metodologia para a compreensão das aulas experimentais, 
uma vez que, os educandos não receberam atividades com roteiros pré-estabelecidos, sendo eles próprios protagonistas de seus experimentos, como sugere Laudan (1986) no que se refere aos problemas empíricos.

Esses fatores podem estar atrelados as orientações conferidas aos educandos sobre os caminhos percorridos para a solução dos problemas, levando-os a assumir parte da responsabilidade por sua aprendizagem, o que, segundo Onuchic et al. (2014) possibilita desenvolver habilidades, criatividade e autonomia no processo de ensino e aprendizagem. Para Pozo (1998, p. 87), essa visão implica no reconhecimento do estudante como sujeito ativo, capaz de pensar, criar e vivenciar novos acontecimentos, considerando "todos aqueles conhecimentos que cada sujeito possui e que adquiriu ao longo de sua vida na interação com o mundo que o cerca e a escola".

No que tange à autoavaliação ocorrida ao final do processo de implementação da proposta, os estudantes sinalizam para uma maior motivação para o trabalho de Resolução de Problemas, assim como consideram ter aprendido novos conhecimentos. Além disso, outra atribuição constatada através dos dados foi a colaboração mútua entre os grupos para a Resolução dos Problemas. O papel da motivação em contextos escolares está diretamente vinculado à direção do comportamento, com vistas à atuação do estudante em determinadas situações. Quando o aluno é motivado à atribuir significados ao assunto estudado, pode ocorrer um maior envolvimento pessoal na solução de situações conflitantes, gerando uma reorganização cognitiva para o aprendizado de novos conceitos e relações (MEDEIROS, 2019). Nesse sentido, Pozo e Crespo (2009, p. 41) argumenta que "motivar é mudar as prioridades de uma pessoa, suas atitudes perante a aprendizagem".

Comparando as categorias utilizadas nos Questionários Inicial e Final é possível observar que houve um significativo progresso quanto à concepção dos alunos a respeito da motivação e o aprendizado de novos conhecimentos a partir do trabalho proposto. As respostas do primeiro questionário podem indicar as dificuldades encontradas pelos estudantes na compreensão dos conteúdos tratados na disciplina, já que as aulas anteriores à esta implementação, eram ministradas de modo que não contemplavam questões socialmente relevantes para os educandos, além de serem dispostas de forma puramente conceitual e matematizada.

Como se apura através dos questionários, a inclusão da temática Drogas aliada à metodologia de Resolução de Problemas, pode ter contribuído para a ressignificação dos conteúdos para os estudantes, configurando-se uma alternativa de articulação entre questões 
contextuais e conceitos científicos, assim como é recomendado na Base Nacional Comum Curricular (BRASIL, 2018), quando sugere que os conteúdos científicos devem fundamentar a realidade do estudante, auxiliando-os no reconhecimento e resolução de problemas atuais e conferindo às disciplinas atribuições interdisciplinares.

\section{CONSIDERAÇÕES FINAIS}

Os resultados obtidos nos questionários contribuem para a avaliação da pertinência no trabalho subsidiado pela metodologia de Resolução de Problemas articulada a temática Drogas na concepção dos estudantes, sujeitos da pesquisa, em relação ao seu processo de aprendizagem. Pela análise do questionário inicial é possível verificar que os estudantes não apresentam uma opinião formada sobre a contribuição da disciplina de Química para sua vida em sociedade, bem como sobre a aprendizagem de novos saberes. No entanto, acreditam tratar-se de uma área do conhecimento que exige uma demanda de raciocínio e por isso é necessário certo esforço para acompanhá-la. Nesse sentido, a metodologia de Resolução de Problemas apresentou-se como uma nova possibilidade didática para esse grupo de educandos, o que reforça as evidências de um estudo de Química, anteriormente tratado através da memorização de conceitos e matematização desta ciência.

Aspectos relacionados às atividades desenvolvidas são mapeadas no questionário final, o que nos permite acreditar que a confluência entre a metodologia de Resolução de Problemas e o uso da temática Drogas ressignificou as estratégias utilizadas na investigação, como forma de motivar os estudantes no estudo de enfoques que envolvam a realidade vivenciada por eles em sociedade. A aprendizagem a partir da metodologia de Resolução de Problemas aliada a temática proposta, mostrou-se potencialmente significativa para despertar nos alunos a criatividade e criticidade, os mobilizando para o conhecimento e habilidades favorecidos por meio de um trabalho teórico e prático, sinalizando uma melhor compreensão dos conceitos científicos articulados a realidade social vivenciada pelos mesmos. Além disso, percebe-se que a temática utilizada despertou nos estudantes curiosidade e motivação para o assunto em estudo, já que a partir do mesmo, os sujeitos desta pesquisa parecem ter conseguido perceber a relevância desta disciplina para a sua vida e sociedade.

Ainda com relação a proposta desse ensaio, verificou-se que os estudantes atribuíram a disciplina de Química outros significados, que não apenas o de memorização de conceitos e a matematização de fórmulas, passando a pensá-la na sua utilidade para as ações cotidianas. Dessa forma, observa-se que os estudantes adquiram os conhecimentos necessários para a 
interpretação dos aspectos relacionados a temática drogas de maneira a poder refletir e atuar de forma consciente no meio em que estão inseridos.

\section{REFERÊNCIAS}

ALEXANDRE, João Welliandre Carneiro; ANDRADE, Dalton Francisco de; VASCONCELOS, Alan Pereira de; ARAUJO, Ana Maria Souza da; BATISTA, Maria Jacqueline. Análise do número de categorias da escala de Likert aplicada à gestão pela qualidade total através da teoria da resposta ao item. In Atas do XXIII Encontro Nac. de Eng. de Produção (ENEGEP). Ouro Preto, MG, 2003.

AULER, Décio. Interações entre ciência-tecnologia-sociedade no contexto da formação de professores de ciências nos acervos da coleção e coletânea do Repositório Institucional da Universidade Federal de Santa Catarina/ SC. 2002. 258f. Tese de Doutorado (Doutorado em Educação) - Universidade Federal de Santa Catarina, Florianópolis, SC, 2002.

AULER, Décio. Alfabetização Cientifico-Tecnológica: Um novo "Paradigma"? Revista Ensaio - Pesquisa em Educação em Ciências, v. 5, n. 1, p. 68 - 83, 2003.

BRASIL. Ministério da Educação. Base Nacional Comum Curricular. Ensino Médio. Homologada pela Portaria ${ }^{\circ}$ 1.570, publicada no D.O.U. de 21/12/2018, Seção 1, Pág. 146, 2018. Disponível em http://portal.mec.gov.br/index.php?option=com_docman\&view=download \&alias=85m121bncc-ensino-medio\&category_slug=abril-2018-pdf\&Itemid=30192. Acesso em: 23 jan. 2019.

BRASIL. Ministério da Educação, Secretaria de Educação Fundamental. Parâmetros curriculares nacionais: Apresentação dos temas transversais, ética / Secretaria de Educação Fundamental. Brasília, 1997. 146 p. Disponível em http://portal.mec.gov.br/seb/arquivos/pdf/livro081.pdf. Acesso em 25 jan. 2019.

BRASIL. Ministério da Educação, Secretaria de Ensino Básico. Parâmetros Curriculares Nacionais para o Ensino Médio. Brasília, DF, 2000. 71 p. Disponível em: http://portal.mec.gov.br/seb/arquivos/pdf/14_24.pdf. Acesso em: 15. fev. 2019.

BRUNER, Jerome. Sobre o Conhecimento: Ensaios de Mãos Esquerda. São Paulo. Phorte, 2008.

D’AMORE, Bruno. Elementos de didática da matemática. Tradução Maria Cristina Bonami. São Paulo: Editora e Livraria da Física, 2007. Tradução de Elementi di didática della matemática.

DELIZOICOV, Demétrio.; ANGOTTI, José André. Física. 2. ed. São Paulo: Cortez, 1992.

ECHEVERRÍA, María del Puy Pérez. A solução de problemas em matemática. In: POZO, J. I. (org.). A solução de problemas: aprender a resolver, resolver para aprender. Porto Alegre: ArtMed, p. 44-65, 1998. 
ECHEVERRÍA, María del Puy Pérez.; POZO, Juan Ignácio (org.). Aprender a resolver problemas e resolver problemas para aprender. In: Pozo, J. I. (Ed.). A solução de problemas: aprender a resolver, resolver para aprender. Porto Alegre: Artmed, p. 13-42, 1998.

FREIRE, Paulo. Pedagogia da Autonomia. 25 ed. Rio de Janeiro: Paz e Terra, 2002.

FLICK, Uwe. Introdução à pesquisa qualitativa. Tradução de Joice Elias Costa. 3. ed. Porto Alegre: Artmed, 2009.

GIL, Antonio Carlos. Como Elaborar Projetos de Pesquisa. 6 ed. São Paulo, Atlas, 2017.

GOI, Mara Elisângela Jappe. Formação de Professores para o Desenvolvimento da Metodologia de Resolução de Problemas na Educação Básica. 2014. 267p. Tese (Doutorado em Educação - Faculdade de Educação) - Universidade Federal do Rio Grande do Sul, Porto Alegre, RS, 2014.

HALMENSCHLAGER, Karine Raquiel. Abordagem de Temas em Ciências da Natureza no Ensino Médio: Implicações na Prática e na Formação Docente. Florianópolis. UFSC. Tese (Doutorado em Educação Científica e Tecnológica). Universidade Federal de Santa Catarina, 2014, p. 1-373.

JUNIOR, Mauro de Souza Lima Prates; NETO, Jose Euzebio Simões. Situações-problema como estratégia Didática para o Ensino de Modelos Atômicos. Revista Brasileira Ensino de Ciências e Tecnologia. v. 8, n. 2, p. 181-201, 2015.

KONDER. Leandro. O Ensino de Ciências no Brasil: um breve resgate histórico. In: CHASSOT, Attico (org.). Ciência, ética e cultura na educação. São Leopoldo: UNISINOS, 1998, p. 32-76.

LAUDAN, Larry. El progreso y sus problemas: Hacia una teoria del crecimiento científico. Madrid: Encuentro Ediciones, 1986.

LEME, Maria Iisabel da Silva. Revisitando a crítica de Bruner: O desvio da proposta cognitivista nos estudos de Solução de Problemas. Revista Psicologia: Reflexão e Crítica, v. 14, n. 3, 2001 .

LOPES, Bernardino Resolução de problemas em Física e Química. Lisboa: Texto Editora, 1994.

MEDEIROS, Denise da Rosa. Resolução de Problemas como proposta metodologia para o Ensino de Química. 2019. 148 p. Dissertação (Mestrado profissional em Ensino de Ciências) - Universidade Federal do Pampa, Caçapava do Sul, RS, 2019.

MENDONÇA, James Madson. A formulação e a Resolução de Problemas nos primeiros anos do Ensino Fundamental. 2017. 157 p. Dissertação (Educação em Ciências) Universidade Federal de Uberlândia, MG, 2019.

ONUCHIC, Lourdes de La Rosa; ALLEVATO, Norma Suely Gomes; NOGUTI, Fabiane Cristina Höpner; JUSTULIN, Andresa Maria (Org.). Resolução de Problemas: Teoria e Prática. Jundiaí: Paco Editorial, 2014. 
PÓLYA, George. O ensino por meios de problemas. RPM - SBM,1995.

POZO, Juan Ignácio (Org.). A solução de problemas: aprender a resolver, resolver para aprender. Porto Alegre: Artmed, 1998.

POZO, Juan Ignácio; CRESPO, Miguel Ángel Gómez. A Solução de Problemas nas Ciências da Natureza. In: POZO, Juan Ignácio.; CRESPO, Miguel Ángel Gómez. A Aprendizagem e o Ensino de Ciências: do conhecimento cotidiano ao conhecimento científico. 5 ed. Porto Alegre: Artmed, 2009.

PRAIA, João Felix. Contributo para uma leitura possível de um percurso profissional. In: CACHAPUZ, Antônio Franscisco.; CARVALHO, Ana Maria Pessoa.; PÉREZ, Daniel Gil (Org.). O Ensino de Ciências como compromisso científico e social: Os caminhos que percorremos. São Paulo: Cortez, 2012. p. 53-74.

SANTOS, Wildson Luiz. Pereira. Contextualização no ensino de ciências por meio de temas CTS em uma perspectiva crítica. Revista Ciência e Ensino, v. 01, número especial, 2007.

SANTOS, Wildson Luiz. Pereira; MORTIMER, Eduardo Fleury. Concepções de professores sobre Contextualização Social do Ensino de Química e Ciências. In Atas da XXII Reunião Anual da Sociedade Brasileira de Química. Poços de Caldas, MG. Livro de Resumos. São Paulo: Sociedade Brasileira de Química, 1999a.

SANTOS, Wildson Luiz. Pereira; MORTIMER, Eduardo Fleury. A Dimensão Social do Ensino de Química - um estudo exploratório da visão dos professores. In Atas do II Encontro Nacional de Pesquisa e Educação em Ciências, Valinhos, 1999 b.

SANTOS, Wildson Luiz. Pereira; MORTIMER, Eduardo Fleury. Uma análise de pressupostos teóricos da abordagem C-T-S (Ciência - Tecnologia - Sociedade) no contexto da educação brasileira. Revista Ensaio Pesquisa em Educação em Ciências, v. 2, n. 2, p. 110$132,2002$.

SANTOS, Flávia Maria Teixeira.; GOI, Mara Elisângela Jappe. Resolução de problemas no ensino de química- fundamentos epistemológicos para o emprego da metodologia na Educação Básica. In Atas ENCONTRO NACIONAL DE ENSINO DE QUÍMICA, ENEQ, 16. e X ENCONTRO DE EDUCAÇÃO QUÍMICA DA BAHIA, EDUQUI, 10., 2012, Salvador, BA, Brasil. Anais eletrônicos [...]. Salvador, BA: Ufba, 2012. Disponível em: http://www.portalseer.ufba.br/ index.php/anaiseneq2012 e http://www.ufrgs.br/forprofciencias/editais/texto3.pdf. Acesso em: 15 nov. 2015.

SILVA, Erivanildo Lopes; MARCONDES, Maria Eunice Ribeiro. Contextualização no Ensino de Ciências: Significados e Epistemologia. In: SANTANA, Eliana; Erivanildo Lopes (Org.). Tópicos em Ensino de Química. São Carlos/SP: Pedro \& João Editores, 2014. 252p.

SILVA, Édila Rosane Alves da. Articulação entre Resolução de Problemas e a temática drogas como proposta metodológica para o Ensino de Química. 2017. 36 p. Trabalho de Conclusão de Curso (Graduação em Licenciatura em Ciências Exatas) - Universidade Federal do Pampa, Caçapava do Sul, RS, 2017. 
SILVA, Édila Rosane Alves da; GOI, Mara Elisângela Jappe. Articulação entre Resolução de Problemas e a temática drogas como proposta metodológica para o Ensino de Química.

Revista Contexto \& Educação, v. 34, n. 107, p. 104-125, 2019 (a).

SILVA, Édila Rosane Alves da; GOI, Mara Elisângela Jappe. Articulação entre Resolução de Problemas e Temáticas no Ensino de Ciências: Uma análise em periódicos da área. Revista Vidya, v. 39, n. 1, 2019 (b).

SILVA, Édila Rosane Alves da. Intervenções teórico-práticas com licenciandos em química por meio de Problemas Temáticos. 2020. 306p. Dissertação (Mestrado em Educação em Ciências) - Universidade Federal de Santa Maria, Santa Maria, RS, 2020.

Recebido em: 25 de maio de 2020.

Aprovado em: 20 de agosto de 2020. 